\title{
Determination of Chlorate and Perchlorate Ions in Drinking Water Using Capillary Electrophoresis
}

\author{
Viktoria V. Sursyakova*a and Anatoly I. Rubaylo ${ }^{\mathrm{a}, \mathrm{b}}$ \\ anstitute of Chemistry and Chemical Technology SB RAS \\ FRC "Krasnoyarsk Science Center SB RAS" \\ 50/24 Akademgorodok, Krasnoyarsk, 660036, Russia \\ ${ }^{b}$ Siberian Federal University \\ 79 Svobodny, Krasnoyarsk, 660041, Russia
}

Received 24.04.2018, received in revised form 18.06.2018, accepted 27.08.2018

\begin{abstract}
In this study it is shown that the chromate background electrolyte suggested early by the authors is suitable for the determination of chlorate and perchlorate ions in drinking water using capillary electrophoresis. The analysis conditions were found allowing one to determine the ions with concentration lower 0.5 of maximum permissible values. The calibration curves were linear within the range of 0.01-0.1 $\mathrm{mM}$ with sample injection at pressure of $50 \mathrm{mbar}$ for $100 \mathrm{~s}$. The method validity was proved by the standard addition method. Using the developed method the real samples of drinking water of Krasnoyarsk were analyzed. Chlorate and perchlorate ions were not found in the sample studied.
\end{abstract}

Keyword: capillary electrophoresis, chlorate ion, perchlorate ion, drinking water.

Citation: Sursyakova V.V., Rubaylo A.I. Determination of chlorate and perchlorate ions in drinking water using capillary electrophoresis, J. Sib. Fed. Univ. Chem., 2018, 11(3), 361-368. DOI: 10.17516/1998-2836-0082.

(C) Siberian Federal University. All rights reserved

* Corresponding author E-mail address: viktoria_vs@list.ru 


\title{
Определение хлорат- и перхлорат-ионов \\ в питьевой воде методом \\ капиллярного электрофореза
}

\author{
В.В. Сурсякова ${ }^{\text {a }, ~ А . И . ~ Р у б а и ̆ л о ~}$ \\ ${ }^{a}$ Институт химии и химической технологии СО РАН \\ ФИЦ «Красноярский научный иентр СО РАН» \\ Россия, 660036, Красноярск, Академгородок, 50/24 \\ ${ }^{6}$ Сибирский федеральный университет \\ Россия, 660041, Красноярск, пр. Свободный, 79
}

В работе показано, что предложенный ранее авторами хроматный фоновый электролит для определения типичных неорганических ионов может быть использован для определения перхлорат- и хлорат-ионов в питьевой воде. Подобраны условия анализа, позволяющие определять ионы с кониентрацией ниже 0,5 ПДК. Установлено, что градуировочные зависимости линейны в диапазоне от 0,01 до 0,1 мМ при вводе пробы при давлении 50 мбар в течение 100 с. Правильностьметодикидоказанаметодом «введено-найдено». Сиспользованием разработанной методики проведен анализ реальных образиов питьевой воды г. Красноярска на содержание перхлорат- и хлорат-ионов. Эти ионы в исследованной воде не обнаружены.

Ключевые слова: капиллярный электрофорез, хлорат-ион, перхлорат-ион, питьевая вода.

\section{Введение}

Одним из основных методом обеззараживания питьевой воды является ее хлорирование, в процессе которого могут образовываться различные хлорсодержащие соединения, в том числе хлорат- и перхлорат-ионы [1]. Кроме того, хлораты и перхлораты используются в качестве ядохимикатов в сельском хозяйстве, присутствуют в отбеливающих и чистящих средствах бытовой химии и могут попадать в речную воду со сточными водами, а затем оказываться и в питьевой воде [2]. Хлораты и перхлораты обладают токсичным действием, в частности, перхлорат-ион полностью ингибирует транспорт йода в щитовидной железе [3]. Значения ПДК для перхлорат- и хлорат-ионов в питьевой воде согласно СанПиН 2.1.4.1074-01 составляют 5,0 мг/л и 20,0 мг/л соответственно [4].

Для определения этих ионов в питьевой воде и других объектах применяют различные методы [1-3, 5-10], часто с использованием дополнитлеьных методов концентрирования: титриметрические, гравиметрические, спектрофотометрические, электрохимические и массспектрометрические методы, капиллярный электрофорез (КЭ), ионная хроматография, жидкостная хроматография с масс-спектрометрическим детектированием. К достоинствам метода КЭ относятся высокая эффективность, низкая себестоимость и высокая экспрессность анализа, малый объем необходимой пробы, возможность определять низкие концентрации ионов без использования дополнительных методов концентрирования. Однако в существующих методиках определения хлорат- и перхлорат-ионов методом КЭ $[7,9]$ используются сложные по соста- 
ву фоновые электролиты, включающие модификаторы электроосмотического потока (ЭОП). Ввиду сложности состава таких электролитов они имеют ограниченный срок хранения. Ранее авторами [11-15] было предложено вместо модификаторов ЭОП применять гидродинамическое давление для подавления электроосмотического потока. Это позволяет использовать более простые по составу фоновые электролиты с большим сроком хранения, что уменьшает себестоимость анализа.

Целью данной работы является разработка методики определения хлорат- и перхлоратионов в питьевой воде методом капиллярного электрофореза с использованием простых по составу фоновых электролитов и гидродинамического давления.

\section{Экспериментальная часть}

Измерения проводили на приборе КРЦКП ФИЦ КНЦ СО РАН - системе капиллярного электрофореза с диодноматричным детектором Agilent ${ }^{3 \mathrm{D}} \mathrm{CE}$ G1600A (Agilent Technologies, USA). Использовали немодифицированный кварцевый капилляр с внутренним диаметром 50 мкм общей длиной 48,5 см (эффективной длиной 40 см). Капилляр термостатировали при температуре $25^{\circ} \mathrm{C}$. Детектирование проводили в УФ-области при 450 нм с опорной длиной волны 375 нм. Использовали напряжение -15 кВ. Для частичного подавления электроосмотического потока использовали гидродинамическое давление 50 мбар. Сигнал детектора обрабатывали при помощи встроенного программного обеспечения HP ChemStation Rev.A.10.02. Ввод пробы гидродинамический при давлении 50 мбар в течение 2-100 с.

Используемые в работе реактивы имели степень чистоты не ниже ч.д.а. Все растворы готовили с применением деионизованной воды, полученной при помощи системы очистки воды Direct-Q3 (Millipore, France) с электропроводностью менее 0,1·10-6 $\mathrm{OM}^{-1} \mathrm{~cm}^{-1}$. Использовали хроматный фоновый электролит 4,7 мM K ${ }_{2} \mathrm{CrO}_{4}, 0,3$ мM K ${ }_{2} \mathrm{Cr}_{2} \mathrm{O}_{7}$ ( $\mathrm{pH}$ 7,25), который готовили следующим образом: в колбу на 100 мл с 50 мл дистиллированной воды добавляли 2,35 мл 200 мМ хромата калия и 0,3 мл 100 мМ дихромата калия, перемешивали и доводили до метки.

Перед работой капилляр последовательно промывали $0,1 \mathrm{M}$ раствором $\mathrm{NaOH}$ в течение 5 мин, затем дважды по 5 мин деионизованной водой, 12 мин - раствором фонового электролита, между анализами - раствором фонового электролита в течение 5 мин.

Разрешение пиков $R_{s}$ рассчитывали с использованием программы ChemStation следующим образом:

$$
R_{s}=\frac{t_{2}-t_{1}}{\left(w_{2}+w_{1}\right) / 2}
$$

где $t_{1}$ и $t_{2}-$ времена миграции соседних пиков; $w_{1}$ и $w_{2}$ - ширина соответствующих пиков, измеренная у их основания.

\section{Результаты и их обсуждение}

Теоретические значения электрофоретических подвижностей хлорат- и перхлоратионов, рассчитанные из табличных значений эквивалентной электропроводности ионов при бесконечном разбавлении [16], составляют 66,9 и $69,7 \cdot 10^{-9} \mathrm{M}^{2} \mathrm{~B}^{-1} \mathrm{c}^{-1}$. Для определения 
ионов с такими подвижностями можно использовать типичный фоновый электролит для разделения неорганических анионов при отрицательной полярности [11, 12, 17-21]: 4,7 мМ $\mathrm{K}_{2} \mathrm{CrO}_{4}, 0,3$ мM K $\mathrm{Cr}_{2} \mathrm{O}_{7}$, pH 7,25. На рис. 1a приведена электрофореграмма разделения 0,5 мМ стандартной смеси хлорат- и перхлорат- ионов с применением хроматного электролита. Как видно на рис. $1 a$, изучаемые ионы разделяются в этих условиях до базовой линии с разрешением пиков $>1.5$. Однако отношение сигнал/шум при вводе пробы при 50 мбар в течение 2 с составляет 3,2 и 5,0 для перхлорат- и хлорат-иона соответственно, что близко к пределу обнаружения, определяемому как концентрация соединения, при котором наблюдаемый пик в 2-3 раза выше уровня шума. В то же время значения ПДК для перхлорат- и хлорат-ионов составляют соответственно 0,05 и 0,24 мМ [4], и согласно ГОСТ Р 8.613-2013 нижняя граница диапазона содержаний определяемого компонента должна быть меньше 0,5 ПДК [22]. Повысить предел обнаружения можно за счет увеличения времени ввода пробы. На рис. $1 b, c$ приведены электрофореграммы разделения перхлорат- и хлорат- ионов с пониженной концентрацией и повышенным временем ввода пробы. Установлено, что при

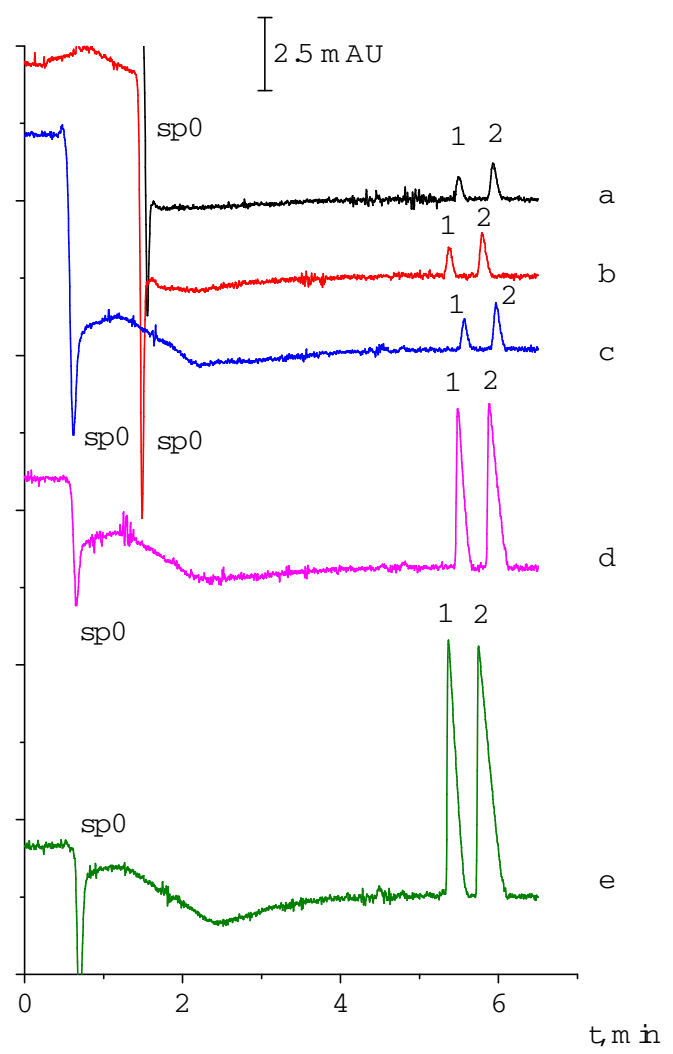

Рис. 1. Электрофореграммы стандартной смеси ионов. Пики: sp0-системный пикс нулевой подвижностью, возникающий на выходном торце капилляра в начальный момент времени; 1 - перхлорат-ион; 2 - хлоратион. Ввод пробы при давлении 50 мбар в течение: а) 2 c, b) 20 c, с-е) 100 с. Концентрация ионов (мМ): a) 0,5 ; b, d) 0,05 ; c) 0,01 ; e) 0,1

Fig. 1. Electropherograms of standard mixture of the ions. Peaks: sp0 is the system peak with null mobility (forming at outlet end of capillary at initial time); 1 - perchlorate ion; 2 - chlorate ion. Sample injection at pressure of 50 mbar for: a) $2 \mathrm{~s}$, b) $20 \mathrm{~s}$. c-e) $100 \mathrm{~s}$. Concentration (mM): a) 0.5, b, d) 0.05 , c) 0.01 , e) 0.1 
вводе пробы при давлении 50 мбар в течение 100 с можно определять концентрации перхлорат- и хлоратионов в 5 и 40 раза меньше ПДК. Предел обнаружения при таком вводе пробы составил 0,01 и 0,006 мМ для перхлорат- и хлорат- ионов, соответственно. Интересно, что при вводе $0.01 \mathrm{mM} \mathrm{смеси} \mathrm{ионов} \mathrm{на} \mathrm{электрофореграмме} \mathrm{наблюдается} \mathrm{смещение}$ маркера ЭОП (рис. 1c) по сравнению с более концентрированными смесями ионов (рис. $1 a$, $b$ ). Вероятно, это связано с низкой электропроводностью пробы, но стоит отметить, что при этом времена миграции исследуемых ионов практически не меняются и данное явление не мешает их определению.

Построены градуировочные зависимости для перхлорат- и хлорат-ионов. Найдено, что эти зависимости линейны $\left(\mathrm{R}^{2}>0,998\right)$ в диапазоне концентраций от 0,01 до 0,1 мМ при вводе 50 мбар*100 с. При увеличении концентрации ионов нарушается симметрия пиков и пики приобретают треугольную форму (рис. $1 d, e$ ). При концентрации ионов 0,1 мМ разрешение пиков составляет 1,6, что приемлемо для количественного анализа.

С использованием разработанной методики проведен анализ реальных образцов питьевой воды, отобранных в Советском и Октябрьском районах г. Красноярска. В исследованных образцах перхлорат- и хлорат-ионы не обнаружены. Пример электрофореграммы питьевой воды и питьевой воды с добавкой исследованных ионов приведен на рис. 2. Правильность методики проверена методом «введено-найдено» (табл. 1). Найдено, что значимые систематические ошибки отсутствуют.

В питьевой воде присутствуют неорганические анионы (хлорид-, сульфат- и нитрат-ионы), системные пики от которых могут накладываться на пики перхлорат- и хлорат- ионов. На рис. 2 видно, что в изученных условиях системные пики не оказывают влияния на разделение изучаемых ионов, так как на электрофореграммах они выходят позже, чем пики перхлорат- и хлорат-ионов. В то же время при использовании другой системы КЭ или капилляра с другой общей и эффективной длиной возможно наложение пиков. В этом случае необходимо подбирать значение применяемого гидродинамического давления, чтобы избежать мешающего влияния системных пиков, как описано в работах $[12,14]$.

Таким образом, показано, что предложенный ранее авторами хроматный фоновый электролит для определения типичных неорганических ионов подходит для определения перхлорат- и хлорат-ионов в питьевой воде. Подобраны условия анализа, позволяющие определять ионы с концентрацией ниже 0,5 ПДК. Оценены диапазон линейности градуировочных зависимостей и предел обнаружения ионов. Проведен анализ нескольких проб питьевой воды г. Красноярска, исследуемые ионы в них не обнаружены. Правильность результатов анализа подтверждена методом «введено-найдено».

Таблица 1. Проверка правильности методики методом «введено-найдено»

Table 1 . Validity check of the method by the standard addition method

\begin{tabular}{ccc}
\hline Ион & Введено, мМ & Найдено, мМ \\
\hline Перхлорат & 0,0100 & $0,0092 \pm 0.0010$ \\
Хлорат & 0,0100 & $0,0105 \pm 0.007$ \\
\hline
\end{tabular}




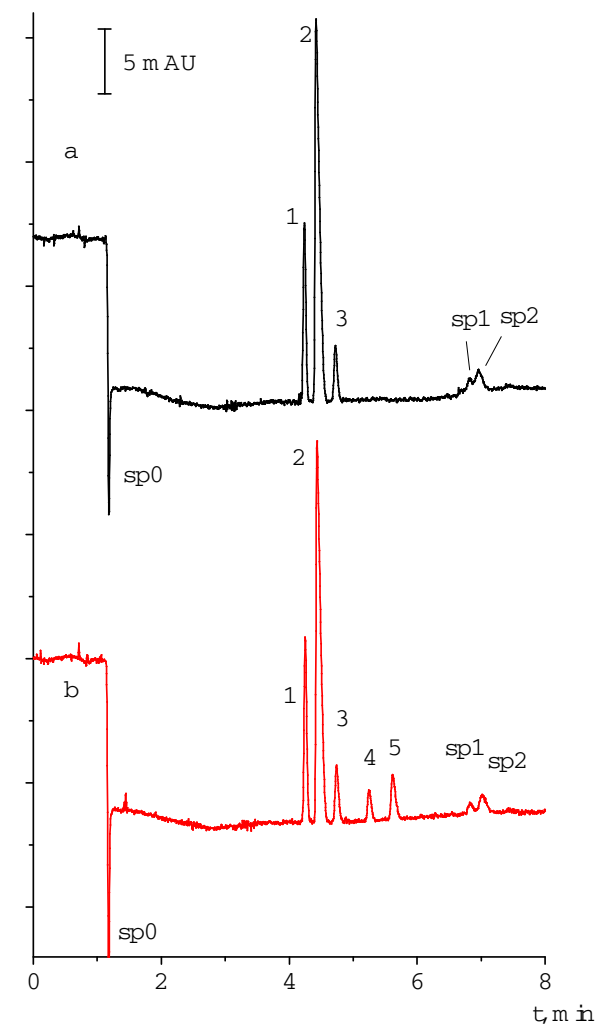

Рис. 2. Электрофореграммы (а) образца питьевой воды, отобранного в Академгородке, и (b) этой же воды с добавкой 0,01 мМ стандартной смеси перхлорат- и хлорат-ионов. Ввод пробы 50 мбар*100 с. Пики: sp0 - системный пик с нулевой подвижностью, 1 - хлорид-ионы; 2 - сульфат-ионы; 3 - нитрат-ионы; 4 перхлорат-ионы; 5 - хлорат-ионы; sp1 - sp2 - системные пики

Fig. 2. Electropherograms of (a) the sample of drinking water obtained in Akademgorodok and (b) this sample with the addition of $0.01 \mathrm{mM}$ standard mixture of the ions. Sample injection at pressure of $50 \mathrm{mbar}$ for $100 \mathrm{~s}$. Peaks: sp0 is the system peak with null mobility, 1 - chloride ion; 2 - sulfate ion; 3 - nitrate ion; 4 - perchlorate ion; 5 - chlorate ion; sp1 and sp2 are the system peaks

\section{Список литературы}

1. Петренко Н.Ф., Деревянко Т.О., Кизлова М.И. Аналитические методы определения в воде диоксида хлора, хлорит- и хлорат-анионов. Актуальные проблемы транспортной медицины 2008. T. 14(4), C. 95-102. [Petrenko N.F., Derevyanko T.A, Kizlova M. I. Analytical methods of determination of chlorine dioxide, chlorite- and chlorate-anions in water. Actual problems of transport medicine 2008. Vol. 14(4), P. 95-102. (In Russ.)]

2. Куликов П.Н., Наянова Е.В., Елипашева Е.В., Сергеев Г.М. Ионохроматографическое определение перхлоратов в питьевой воде с предварительным микроэкстракционным концентрированием. Аналитика и контроль 2014. T. 18(1), C. 76-81. [Kulikov P.N., Nayanova E.V., Elipasheva E.V., Sergeev G.M. Ion chromatography determination of perchlorate in drinking water with a preliminary microextraction concentration. Analytics and contol 2014. Vol. 18(1), P. 76-81. (In Russ.)].

3. Iannece P., Motta O., Tedesco R., Carotenuto M., Proto A. Determination of perchlorate in bottled water from Italy. Water 2013. Vol. 5(2), P. 767-779. 
4. СанПиН 2.1.4.1074-01. Питьевая вода. Гигиенические требования к качеству воды иеентрализованных систем питьевого водоснабжения. Контроль качества. М.: Минздрав России, 2002. 104 c. [SanPiN (Russian Sanitary Standard) 2.1.4.1074-01. Drinking Water. Public Health Water Quality Requirements for Centralized Drinking Water Supply Systems. Quality Control. Moscow: Ministry of Health of Russia, 2002, 104 p. (In Russ.)]

5. Urbansky E.T. Quantitation of perchlorate ion: practices and advances applied to the analysis of common matrices. Critical Reviews in Analytical Chemistry 2000. Vol. 30(4), P. 311-343.

6. Khimchenko S.V., Eksperiandova L.P., Blank A.B. Adsorption-spectrometric and test methods for determining perchlorate ions with thionine on polyurethane foam. Journal of Analytical Chemistry 2009, Vol. 64(1), P. 14-17.

7. Будников В.Н., Давыдов М.В., Спиридонов В.А., Будникова И.К. Определение неорганических анионов применительно к исследованию смесевых взрывчатых веществ, пиротехнических составов, продуктов их взрыва и сгорания методом капиллярного электрофореза. Теория и практика судебной экспертизы 2010, Т. 20(4), C. 208-214. [Budnikov V.N., Davydov M.V., Spiridonov V.A., Budnikov I.K. Detection of non organic anions with regard to the mixed explosives, pyrotechnic compositions, products of their blasts and burning by means of the capillary electrophoresis method. Theory and Practice of Forensic Science 2010, Vol. 20(4), P. 208-214. (In Russ.)]

8. Сериков Ю.А., Серкова Н.В. Титриметрический метод определения хлорат-иона в природных водах. Заводская лаборатория. Диагностика материалов 2010. Т. 76(10), C. 21-24. [Serikov U.A., Serkova N.V. Titrimetric method of determination of chlorate ions in natural water. Zavodskaya Laboratoiya. Diagnostika materialov 2010. Vol. 76(10), P. 21-24. (in Russ.)]

9. Методика М 01-52-2012. Определение хлорат-, перхлорат- и хлорит-ионов в питьевых водах, в том числе расфасованных в емкости. СПб.: Люмэкс, 2012. 20 с. [Method M 01-52-2012. Determination of chlorate, perchlorate, and chlorite ions in drinking water including bottled water. St. Petersburg: Lumex, 2012. 20 p. (in Russ.)]

10. Elipasheva E.V., Kamasheva A.S., Kulikov P.N., Sergeev G.M. Extraction-photometric selective determination of trace perchlorates in potable waters. Journal of Analytical Chemistry 2013, Vol. 68(7), P. 590-594.

11. Kalyakin S.N., Sursyakova V.V., Burmakina G.V., Rubailo A.I. Hydrodynamic suppression of the electroosmotic flow in capillary electrophoresis with indirect spectrophometric detection. Journal of Analytical Chemistry 2009. Vol. 64(4), P. 398-403.

12. Sursyakova V.V., Kalyakin S.N., Burmakina G.V., Rubaylo A.I. System peaks and optimization of anion separation in capillary electrophoresis with non-reversed electroosmotic flow. Journal of Analytical Chemistry 2012. Vol. 67(9), P. 783-789.

13. Sursyakova V.V., Rubaylo A.I. New peak broadening parameter for the characterization of separation capability in capillary electrophoresis. Journal of Separation Science 2015. Vol. 38(4), P. 690-696.

14. Sursyakova V.V., Kalyakin S.N., Burmakina G.V., Rubaylo A.I. System peaks in capillary zone electrophoresis of anions with negative voltage polarity and counter-electroosmotic flow. Electrophoresis 2011. Vol. 32(2), P. 210-217.

$$
-367-
$$


15. Sursyakova V.V., Burmakina G.V., Rubaylo A.I. Strategy for non-target ionic analysis by capillary electrophoresis with ultraviolet detection. Analytical and Bioanalytical Chemistry 2017. Vol. 409(4), P. 1067-1077.

16. Lide D.R. Handbook of Chemistry and Physics. Boca Raton: CRC Press, 2003. 932 p.

17. Сурсякова В.В., Калякин С.Н., Бурмакина Г.В., Рубайло А.И. Использование внутреннего стандарта при определении анионов методом капиллярного электрофореза с косвенным спектрофотометрическим детектированием. Журнал Сибирского федерального университета. Химия 2009. T. 2(1), C. 42-47. [Sursyakova V.V., Kalyakin S.N., Burmakina G.V., Rubaylo A.I. The using of internal standard in determination of anions by capillary electrophoresis technique with indirect spectrophotometric detection. Journal of Siberian Federal University. Chemistry 2009. Vol. 2(1), P. 42-47. (In Russ.)]

18. Сургутскова А.Г., Бурмакина Г.В., Сурсякова В.В., Рубайло А.И. Применение метода высокоэффективного капиллярного электрофореза для мониторинга анионного состава пресноводных экосистем на примере реки Енисея. Журнал Сибирского федерального университета. Химия 2009. T. 2(3), C. 266-274. [Surgutskova A.G., Burmakina G.V., Sursyakova V.V., Rubaylo A.I. The using of high-performance capillary electrophoresis technique for monitoring of freshwater ecosystems by example river Yenisei. Journal of Siberian Federal University. Chemistry 2009. Vol. 2(3), Р. 266-274. (In Russ.)]

19. Бондарева Л.Г., Калякина О.П., Бурмакина Г.В., Сурсякова В.В., Калякин С.Н., Рубайло А.И. Исследование анионного состава объектов окружающей среды промышленной зоны г. Красноярска методами ионной хроматографии и капиллярного электрофореза. Журнал Сибирского федерального университета. Химия 2009. T. 2(4), C. 368-376. [Bondareva L.G., Kalyakina O.P., Burmakina G.V., Sursyakova V.V., Kalyakin S.N., Rubailo A.I. The Study of anionic composition of the environment of the Krasnoyarsk's industrial zone by ion chromatography and capillary electrophoresis. Journal of Siberian Federal University. Chemistry 2009. Vol. 2(4), P. 368-376. (In Russ.)]

20. Гуляева У.Е., Калякина О.П., Качин С.В., Полынцева Е.А., Сурсякова В.В., Азнаева М.Р. Применение ступенчатого элюирования для определения некоторых органических и неорганических анионов в снежном покрове. Фундаментальные исследования 2012. № 6, С. 689693. [Gulyaeva U.E., Kalyakina O.P., Kachin S.V., Polyntseva E.A., Sursyakova V.V., Aznaeva M.R. Applying of stepwise elution for determination of some organic and inorganic anion in snow cover. Fundamental Research 2012. № 6, Р. 689-693. (In Russ.)]

21. Сурсякова В.В., Рубайло А.И. Изучение мешающего влияния органических кислот на определение фторид-ионов методом капиллярного электрофореза с применением хроматного фонового электролита. Журнал Сибирского едерального Университета. Химия 2017. Т. 10(4), C. 573-579. [Sursyakova V.V., Rubaylo A.I. Interfering influence of organic acids anions on the determination of fluoride ions by capillary electrophoresis using chromate background electrolyte. Journal of Siberian Federal University. Chemistry 2017. Vol. 10(4). 573-579. (In Russ.)]

22. ГОСТ Р 8.613-2013. Государственная система обеспечения единства измерений. Методики (методы) измерений состава и свойств проб вод. Общие требования к разработке. М.: Стандартинформ, 2014. 12 c. [GOST R 8.613-2013. State system for ensuring the uniformity of measurements. The procedures (methods) of measurements of structure and properties of water samples. General requirements to development. Moscow: Standardinform, 2014. 12 p. (In Russ.)] 